\title{
Price image and the sugrophobia effect on luxury retail purchase intention
}

\begin{abstract}
Consumer shopping behavior in luxury retail stores continues to be a subject of interest among marketing researchers. Such a phenomenon has led us to explore how price image and sugrophobia, a psychological feeling of being taken advantage of, would influence consumers' future behavioural intention in the context of luxury retail store. Informed by a survey of 400 consumers, this study adopts the Stimulus-Organism-Response (S-O-R) model to examine how price image triggers consumer perceptions (i.e., perceived value, trust and attitude) and results in behavioral intention. Sugrophobia is included in the S-O-R model to assess its moderating effect. Data analysis using SEM-PLS demonstrates that a retailer's price image has a positive effect on consumers' perceived value, trust, attitude, and future behavioral intention. Sugrophobia, in turn, is found to weaken the relationship between price image and consumer perceptions. The study thus highlights the relevance of sugrophobia among risk-averse consumers and the necessity to manage sugrophobic consumers effectively in the context of a luxury retail store. Implications of the study are discussed.
\end{abstract}

Keyword: Price image; S-O-R model; Sugrophobia; Behavioral intention; Luxury retail 